\title{
HASIL PENGUKURAN PARTIKEL ASAP GROUND PERTICLES GENERATOR (GPG) DI LAB TMC PUSPIPTEK SERPONG PADA 11 APRIL 2013
}

\author{
R. Djoko Goenawan ${ }^{1}$, Untung Haryanto ${ }^{1}$, Pitoyo Sarwono Sudibyo ${ }^{1}$, \\ Bambang Asmoro ${ }^{1}$ \& Pamuji $i^{2}$ \\ 1. Unit Pelaksana Teknis (UPT) - Hujan Buatan, Badan Pengkajian dan Penerapan Teknologi \\ (BPPT), \\ 2. Pusat Teknologi Keselamatan dan Metrologi Radiasi (PTKMR)- BATAN
}

\begin{abstract}
ABSTRAK
Telah dilakukan pengukuran distribusi dan konsentrasi asap partikel dari hasil penyalaan GPG yang dilakukan di Lap TMC - Puspiptek Serpong. Alat yang digunakan dalam pengukuran baik besar, distribusi dan konsentrasi partikel adalah menggunakan LightHouse (LH) yang bisa menampilkan secara langsung dalam layar monitor alat tersebut. Yang secara langsung terbaca dalam monitoring LH adalah besar partikel dan jumlah partikel per satuan volume (m3). Kisaran alat pengukur partikel LH bisa mengukur terkecil 0.3 mikron hingga 5 mikron dengan rincian 0.3, 0.5, 1.0, 2.5, dan 5 mikron. Light House (LH) adalah satu satunya alat yang biasa digunakan untuk pengukuran udara dan lingkungan dari Laboratorium Aerosol, PTKMR BATAN. Telah dilakukan pengukuran partikel dari asap GPG (Ground Particles Generator) sebanyak 21 kali sampling. Sekali pegambilan sampling asap diperlukan waktu sebanyak 5 menit dan pengukuran udara dalam wadah sampling tersebut juga diperlukan waktu sekitar 5 menit. Selain pengukuran dengan menggunakan LH, juga dilakukan pengukuran dengan menggunakan Impaktor Kaskade Type Anderson dengan 12 tingkat yang memungkinkan pengukuran dari 0.1 mikron hingga 9 mikron. Waktu yang diperlukan cukup lama, yaitu antara pukul 13.15 hingga 18.15 WIB yaitu 5 jam. Impaktor tidak bisa langsung terbaca hasil pengukuran partikelnya namun harus di proses kemudian di kondiskan serta dilakukan penimbangan partikel yang mengendap di setiap tingkatan, sehingga bisa diketahui distribusi partikel tersebut setiap tingkat dari 0.1 mikron hingga partikel terbesar yaitu 9 mikron. Hasil sementara dari pengukuran menggunakan LH dari sebanyak 21 sampel adalah untuk partikel 0.3 mikron memiliki jumlah partikel terbesar mencapai $495.466 .815 / \mathrm{m}^{3}$ atau 495 partikel/ $/ \mathrm{cm}^{3}$ asap dan terkecil sebanyak $51.767 .763 / \mathrm{m}^{3}$ atau 52 partikel/ $\mathrm{cm}^{3}$ asap. Sementara, untuk partikel yang terukur 0.5 mikron terbanyak mencapai $8.969 .923 / \mathrm{m}^{3}$ atau 9 partikel/ $\mathrm{cm}^{3}$ asap dan terkecil 84.755 .200 partikel/ $\mathrm{cm}^{3}$ atau 85 partikel/ $\mathrm{cm}^{3}$. Sedangkan, partikel yang terukur 1.0, 2.5 dan 5.0 mikron di LH tidak terpantau atau tidak ada sama sekali alias Nol (skala $1 \mathrm{~cm}^{3}$ ). Tampak puncak distribusinya diperkirakan kurang dari 0.3 mikron (antara 0.1 - 0.05 mikron), sebagai "tail" kanan distribusi (jika dianggap normal) adalah 0.5 mikron. Perkiraan tersebut akan di buktikan dengan menggunakan Impaktor yang bisa mengukur partikel terkecil 0.1 mikron.
\end{abstract}

\begin{abstract}
Measurement of Concentration Distribution and smoke particles from the ignition GPG conducted in TMC-Lab Puspiptek Serpong. Measurement tool used in both large, the distribution and concentration of particles is using Light-House (LH) which can display directly in the device monitor screen which is directly readable in monitoring large particles and $\mathrm{LH}$ is the number of particles per unit volume (m3). LH range of gauges can measure the smallest particles 0.3 microns to 5 microns with the details $0.3,0.5,1.0,2.5$ and 5 microns. Light House (LH) is the only tool used to measure air and environment of the Aerosol Laboratory, PTKMR BATAN in Jakarta. Have performed measurements of the smoke particles GPG (Ground Particles Generator) as much as 21 times the sampling. Once pegambilan sampling smoke take as many as 5 minutes and air
\end{abstract}


measurements in the sampling container also takes about 5 minutes as well. In addition to measurements by using $\mathrm{LH}$, also be measured by using the cascade Impaktor Type Anderson with 12 levels that allow measurement of 0.1 microns to 9 microns. It takes quite a long time, which is between 13:15 to 18:15 hrs ie 5 hour. Impaktor can not directly read the results of measurements of the particles but must be in process later in kondiskan and sediment particles weighing is done at every level, so they can know the distribution of particles of 0.1 microns each level until the largest particles is 9 microns. Interim results of measurements using as many as 21 samples of $\mathrm{LH}$ is for 0.3 micron particles have the greatest number of particles reaching 495 partikel/ $\mathrm{cm}^{3} 495.466 .815 / \mathrm{m}^{3}$ or as much smoke and the smallest 52 partikel/ $\mathrm{cm}^{3} 51.767 .763 / \mathrm{m}^{3}$ or smoke. While, for the measured particles 0.5 microns or 9 the highest reaches $8.969 .923 / \mathrm{m3}$ partikel/cm3 smoke and smallest partikel/ $/ \mathrm{m}^{3} 84,755,200$ or 85 partikel/ $\mathrm{cm}^{3}$. Whereas, particles measured 1.0, 2.5 and 5.0 microns in LH is not monitored or none at all, aka Zero. Looks peak distribution estimated to be less than 0.1 microns, as the "tail" distribution right (if it is considered normal) is 0.5 microns. The estimate will be proved by using Impaktor that can measure the smallest particles of 0.1 microns.

Kata Kunci : partikel asap, Ground Particles Generator, konsentrasi dan distribusi

\section{PENDAHULUAN}

Isu pemanasan global (global warming) dan climate change (baik cuaca dan iklim ekstrim) yang akhir-akhir ini menjadi pembicaraan para peneliti, baik di tingkat internasional maupun nasional, dampaknya mulai dirasakan banyak orang termasuk di Indonesia. Dampak nyata dari pemanasan global adalah meningkatnya suhu udara (akibat dari efek rumah kaca), naiknya permukaan laut (akibat pencairan es di kutub), dan berubahnya pola cuaca, musim dan iklim, sehingga mengakibatkan adanya perubahan neraca air di permukaan (curah hujan berkurang, ketersediaan air tanah berkurang) di sisi lain atau wilayah tertentu sementara di wilayah lain pada saat bersamaan terjadi hal yang sebaliknya. Dari aspek sebaran hujan secara temporal, telah terjadi perubahan pola musim di Indonesia yang biasanya 6 bulan musim hujan dan 6 bulan musim kemarau. Kini pola ini tidak pernah terjadi lagi, perbandingannya bergeser menjadi 5 atau 4 bulan musim hujan dan 7 atau 8 bulan musim kemarau. Dari aspek sebaran spasial (keruangan), tidak meratanya curah hujan di wilayah pulau-pulau Indonesia. Sementara di suatu daerah berlangsung hujan lebat yang mengakibatkan banjir dan tanah longsor, di daerah lain mengalami kekurangan air akibat hujan tidak turun. Unit Pelaksana Teknis (UPT) Hujan Buatan di BPPT yang sekarang dikenal sebagai TMC (Teknologi Modifikasi Cuaca) bertugas merekayasa kondisi atmosfer melalui penyemaian awan, agar berlangsung proses pertumbuhan awan hujan lebih cepat, sehingga menghasilkan curahan hujan yang lebih besar dan lebih cepat jatuh ke permukaan bumi (jadi tidak membuat hujan, melainkan merangsang pertumbuhan awan hujan).

Unit Pelaksana Teknis Hujan Buatan BPPT berdiri sejak tahun 1976 hingga sekarang ini terus menerus secara intensif dan aktif melakukan pelayanan operasional Hujan Buatan (TMC) tidak hanya untuk program menambah hujan (rain enhancement) akan tetapi juga sejak tahun 2002 telah melakukan TMC Redistribusi awan (cloud dispersal) dan rain-suppression (pengurangan hujan) di Palembang pada saat kegiatan Sea Games (2011), Pekanbaru (2012) dan Jabodetabek (2013). Sejalan dengan hal tersebut, dipandang perlu untuk melakukan dan memperkuat R\&D dalam bidang TMC dan rekayasa atmosfer guna mengantisipasi bencana alam yang disebabkan oleh cuaca (atmosfer dan awan) yang salah satunya karena pengaruh aktivitas manusia yang sudah mengglobal (global warming) dan climate change (cuaca dan iklim ekstrim) yang semakin ekstrim. Pada saat El-Nino 1997-1998 NCAR dan UPT Hujan Buatan BPPT telah bekerjasama untuk mengkaji dan meneliti serta melakukan pengukuran aerosol dan efek kebakaran hutan dan asap yang terbesar yang pernah melanda belahan bumi hingga di Indonesia. Sementara UPT Hujan Buatan hingga saat ini belum memiliki peralatan untuk melakukan pengukuran Aerosol dan CCN (cloud condensation nuclei) yang sangat penting dalam setiap kegiatan TMC atau penyemaian awan baik untuk Rain Enhancement maupun Rain Suppression, padahal peralatan tersebut adalah wajib dan sebagai SOP Standart sebagai syarat untuk melakukan TMC seperti di negara lain yaitu Thailand dan China. Perlu diketahui bahwa UPT Hujan Buatan sejak tahun 2009 telah merencanakan untuk memiliki Aerolab namun 
2011 hanya memiliki pesawatnya saja (Pipper Chayen) yang mendukung dan siap dipasang peralaratan tersebut.

Untuk itu, dalam kegiatan penyemaian dengan sistem kompetisi telah dibuat GPG versi Palembang dan DKI. Diharapkan dengan sistem kompetisi ini udara di kondisikan dengan menginjeksikan partikel higroskopis sebanyak 200-300 partikel per $\mathrm{cm}^{3}$. Sementara UPT Hujan Buatan belum memiliki peralatan pengukuran dan pengujian baik untuk aerosol udara maupun asap partikel yang dihasilkan dari penyalaan GPG selama kegiatan TMC baik di Palembang 20111 maupun di Jabodetabek 2013. Dengan bekerjasama dengan Laboratorium Aerosol BATAN dalam pengukuran asap partikel GPG. Hanya 2 (dua) alat pengukur aerosol dan polutan yang sering digunakan BATAN yaitu Light House dan Impaktor Anderson.

\section{ALAT DAN PENGUKURAN}

METODE

Sebagai acuan dan analogi dalam pembentukan aerosol dan awan, keberadaan partikel aerosol di atmosfer (sebagai back ground) akan mempengaruhi kondisi iklim di bumi, khususnya dalam proses terbentuknya awan $[1,2]$. Partikel aerosol dari penguapan air laut tidak hanya mengandung dominasi $\mathrm{NaCl}$ akan tetapi juga mengandung Calsium Cloride $\left(\mathrm{CaCl}_{2}\right)$ dan ammonium sulfat $\left(\left(\mathrm{NH}_{4}\right)_{2} \mathrm{SO}_{4}\right)$ dengan diameter antara $10-40 \mathrm{~nm}(0,01-0,04$ $\mu \mathrm{m})$ dalam mode Aitken diyakini sebagai sumber nuklei kondensasi awan (CCN) [3, 4, 5]. Partikel sangat kecil ini sangat higroskopis dan mudah terkondensasi [6]. Ada korelasi yang linier antara nuklei kondensasi (CN) dan nuklei kondensasi awan (CCN) Di atas permukaan laut, konsentrasi nuklei kondensasi (CN) berkisar antara 100 400 partikel $/ \mathrm{cm}^{3}$ [7]. Menurut penelitian dan simulasi model awan, jika partikel aerosol di udara kurang dari 100 partikel per cm3 dan besar partikel lebih dari 2 mikron maka awan dengan mudah terbentuk menjadi hujan sebaliknya jika partikel yang dominan lebih kecil dari 2 mikron dan banyaknya aerosol sebagai CCN berkisar antara $100-400$ partikel $/ \mathrm{cm}^{3}$ maka akan terjadi kompetisi terbentuknya ccn di udara, penyerapan uap air dari aerosol menjadi ccn terjadi merata dan udara menjadi stabil sehingga lama menjadi awan dan sulit terbentuk hujan. Berdasarkan uraian di atas, maka perlu dipahami proses pembentukan awan dan karakteristiknya. Oleh karena itu perlu dilakukan penelitian partikel aerosol sebagai background dan kita rekayasa dengan menginjeksikan partikel sebanyak mungkin dan dengan ukuran kurang dari 2 mikron sehingga akan terjadi kompetisi di udara agar awan sulit berkembang menjadi hujan. Dengan memanfaatkan peralatan yang dimilik oleh Lab Aerosol - PTKMR BATAN. Kerjasama antara UPT Hujan Buatan dan BATAN dalam penelitian ini diharapkan mampu memberikan informasi karakterisasi partikel asap yang keluar dari cerobong GPG, sehingga penyemaian awan dengan sistem kompetisi dari asap partikel GPG dapat berlangsung dengan optimal.
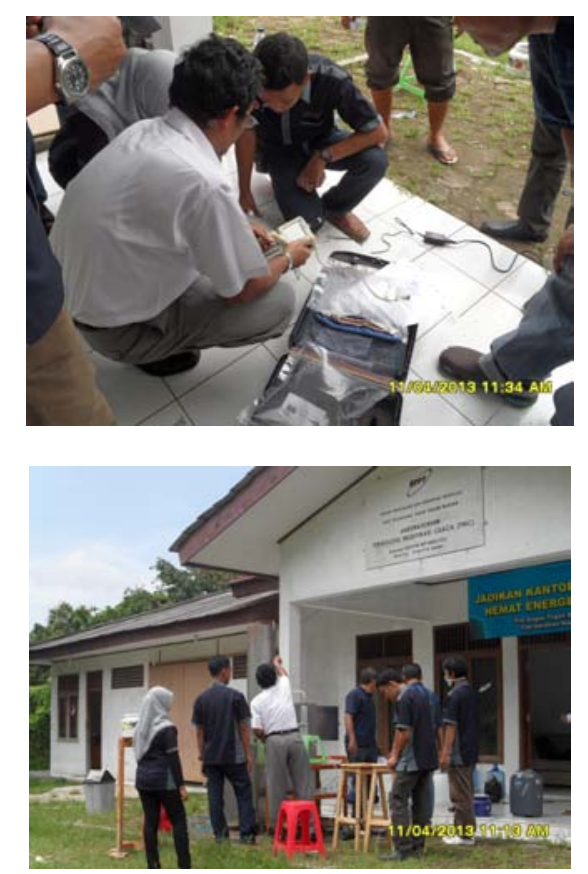

Gambar 1. Kiri adalah Light House dan Kanan adalah Impactor Cascade Anderson

Pengambilan sampel atau sampling menggunakan Light House dilakukan bertahap. Pertama Kantong sampel dibuka, kemudian alirkan asap partikel GPG dengan pipa logam dan disambungkan ke kantong plastic Templar serta dihubungkan dengan generator pengisap udara. Setelah asap yang mengandung partikel terisi penuh masuk ke dalam kantong sampel, segera berhentikan pompa isap dan tutup saluran kantong agar sampel asap tidak keluar. Selanjutnya, hubungkan Lihgt House dengan saluran kantong sampel yang berisi asap partikel GPG tersebut. Hingga sekitar 5 menit, secara perlahan hingga asap dalam kantong sampel asap tersebut mulai mengalir keluar masuk ke Light House (LH) dan mulai terlihat jumlah partikel dan besar partikel yang terukur di layar LH. 


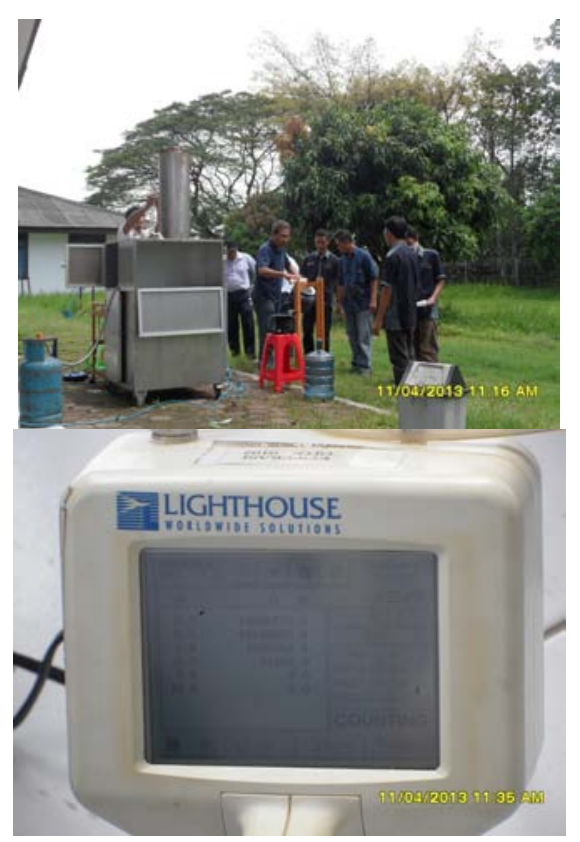

Gambar 2. Pengukuran Partikel GPG (kiri) dan hasil sampling dengan Light House (kanan)

Sedangkan, pengukuran partikel tidak langsung dengan melakukan pengambilan sampel dilakukan menggunakan alat cascade impactor yang dihubungkan dengan pompa vakum dengan laju alir 28,3 liter per menit. Bagan alir pengambilan sampel dengan cascade impactor ditunjukkan pada Gambar 3. Filter paper Whatman 41 dengan porositas 0,1 $\mu \mathrm{m}$, Ashless England dan filter mylar buatan Taiyo, yang digunakan masing-masing berdiameter 8,1 $\mathrm{cm}$. Setiap satu set plat impaksi berisi satu filter dan dimasukkan ke dalam wadah CD yang diberi label meliputi: nomor contoh, lokasi pencuplikan, jenis contoh, dan tanggal pengambilan contoh. Delapan filter mylar dan sebuah filter whatman tersebut sebelum digunakan, disimpan 24 jam di dalam desikator, agar terhindar dari pengaruh penambahan berat dari kelembaban udara. Kemudian ditimbang dengan timbangan analitik dan ditutup rapat dengan seal. Partikel dari asap partikel GPG yang ada di filter didestruksi, diatur $\mathrm{pH}$ larutan sebesar 2, dan ditambahkan $10 \mathrm{ppm}$ Mo sebagai internal standar. Larutan ditambahkan dengan $5 \mathrm{ml}$ larutan 2\% Amonium Pirolydine Dithio Carbamat (APDC), dan diaduk selama 30 menit dengan magnetik stirrer, serta saring endapan yang terbentuk dengan filter millipore.
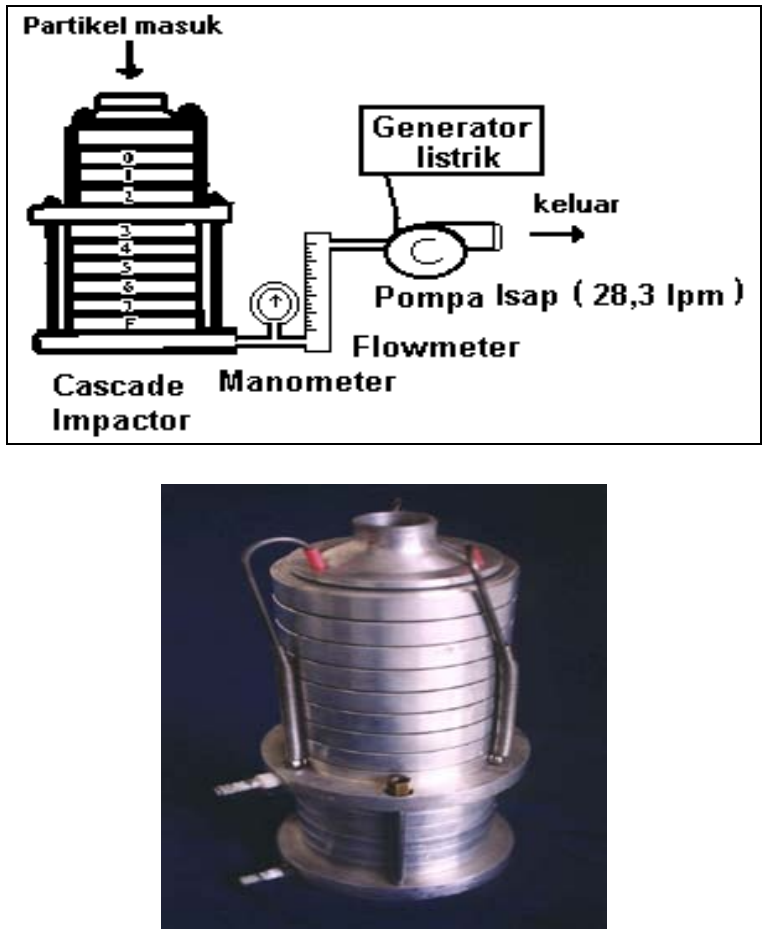

Gambar 3. Sistem pengambilan sampel partikel dengan cascade impactor Andersen

Pengukuran partikel asap dari cerobong GPG di Gedung Workshop TMC, PUSPIPTEK, Serpong Jawa Barat pada tanggal 11 April 2013. Sebelumnya di awali dengan kondisi GPG yang belum di upgrade baik dari kinerja GPG maupun konsentrasi larutan yang masih rendah. Hasil pengukuran awal, namun hasilnya masih dianggap dan terlalu kecil yaitu 149 partikel per $\mathrm{cm}^{3}$ asap yang dilakukan pada tanggal 18-19 Februari 2013 di Atap Gedung Parkiran BPPT, Jakarta.

\section{HASIL PENGUKURAN DAN PEMBAHASAN}

Hasil pengukuran partikel asap dari cerobong GPG yang telah di upgrade baik kinerja produksi partikel maupun meningktkan konsentrasi larutan. Sebelumnya, perlu diketahui bahwa alat Light House tidak bisa dan tidak direkomendasikan dalam mengukur asap partikel dari bahan-bahan yang bersifat higroskopis dan korosif. Oleh karena itu, bahan semai dalam larutan GPG yang semula adalah $\mathrm{CaCl}_{2}$ dan $\mathrm{MgCl}_{2}$ pada saat dilakukan pengukuran dengan $\mathrm{LH}$ harus diganti dengan bahan semai $\mathrm{Ca}(\mathrm{OH})_{2}$ yang tidak bersifat korosif. Tingkat kelarutan bahan semai yang sesungguhnya sebagai bahan partikel yang digunakan dalam TMC sistem kompetisi lebih banyak terlarut daripada bahan semai yang 
terlarut yang digunakan selama sampling pengukuran baik dengan LH maupun Kaskade Impaktor Anderson, sehingga partikel yang dihasilkkan sesungguhnya jauh lebih banyak dari daripada yang terukur dari bahan semai selama pengukuran karena demi keamanan alat LH. Namun demikian, pengukuran tetap harus dilakukan agar kita tahu bahwa GPG sesuai dengan rekomendasi dan harapan para ahli serta agar partikel yang tersebar ke udara dari cerobong asap GPG dapat bekerja secara optimal sehingga terjadi kompetisi uap air sebanyak mungkin dapat di serap dari partikel yang sangat halus kurang dari 1 mikron. Sebagai pelarut dan sekaligus BBM juga di ganti juga karena pelarut dan terlarut tidak bisa diganti atau ditukar sebagai pelarut maupun sebagai bahan terlarut.

Sebagai perbandingan, hasil pengukuran partikel aerosol di permukaan (background) dilakukan di Gunung Mas dan Teluk Naga diperoleh ukuran partikel besar $(r>\square \mathrm{m}$ atau diameter $>2$ mikron). Sementara dari hasil pengukuran dari LH (Gambar 2) menunjukkan bahwa partikel asap GPG dominan berdiameter antara 0.3 dan 0.5 mikron. Dari data sebanyak 21 yang di sampling, terbanyak mencapai 495.466.815 partikel $/ \mathrm{m}^{3}$ dan terkecil 51.767.763 partikel $/ \mathrm{m}^{3}$ sementara partikel dengan ukuran 0.5 mikron terbanyak hanya mencapai 84.755.200 partikel $/ \mathrm{m}^{3}$ dan terkecil 8.969.923 partikel $/ \mathrm{m}^{3}$. Hal ini jika dari tinjauan aspek kelarutan bahan semai terbanyak dan terkecil sesuai dengan jumlah produksi partikel terbanyak dan terkecil dari asap yang keluar dari cerobong GPG. Sebagai perbandingan, partikel terkecil untuk partikel baik 0.3 dan 0.5 mikron dengan komposisi pelarut dan terlarut dengan perbandingan $3: 0.3$ volume dan terbesar nya pada 3 : 0.9 volume. Peningkatan produksi partikel asap hasil pembakaran sebanding dengan tingkat kelarutan bahan semai dalam larutannya. Selain kelarutan bahan semai yang terlarut dibuat jenuh, kinerja GPG ditingkatkan juga antara lain mengkonsentrasikan dan meningkatkan intensitas nyala api pada saat sebelum dan sesudah bertemu antara butiran bahan semai dengan titik api GPG. Hasil pengukuran asap partikel GPG tersebut jika ditinjau dan digunakan alat pengukur Light House tampak bahwa puncak distribusi Normalnya adalah antara 0.3 mikron dan lebih halus (kecil) lagi ukuran partikelnya (lebih kecil dari 0.3 mikron bisa 0.1 dan atau 0.05 mikron) sayangnya di Indonesia dalam hal ini BATAN, hanya memiliki alat ukur terkecil pada partikel dengan diameter 0.1 mikron (Kaskade Impaktor) dan 0.3 mikron (Light House). "Tail" kanan dari distribusi normal partikel dari asap partikel yang dihasilkan oleh GPG adalah 0.5 mikron dan 1.0 mikron untuk konsentrasi volume asap setiap 1 $\mathrm{cm}^{3}$. Namun demikian, persyaratan untuk melakukan TMC dengan metode kompetisi sudah terpenuh yaitu kurang dari 2 mikron (Yan \& Rossenfeld, 2012) dengan konsentrasi antara 100-400 partikel/cm ${ }^{3}$ (Schaefer, 1992). Sehingga jika digabung antara partikel 0.3 dan 0.5 mikron menjadi 546 partikel $/ \mathrm{cm}^{3}$ (terbanyak) dan 135 partikel/cm ${ }^{3}$ (terkecil). Dimana kinerja GPG baik selama pengukuran dan dilapangan selama operasi TMC dalam mereduksi hujan telah mampu bekerja hingga 10 jam lebih, bahkan jika semua mendukung secara teknis dan operasional mampu bekerja mendekati 24 jam penuh dengan istirahat kurang lebih 1 jam.

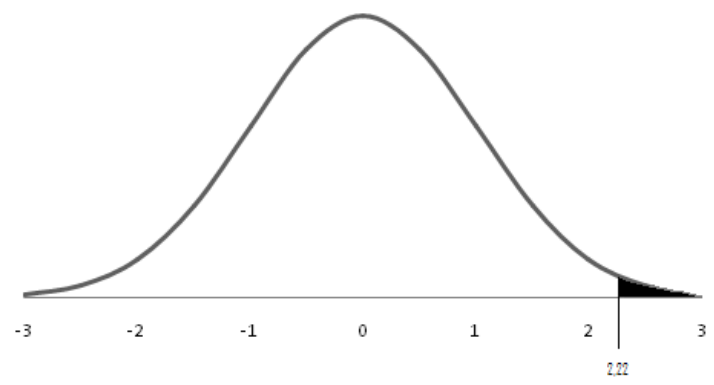

Gambar 4. Ilustrasi Diagram Distribusi Normal Pengukuran Partikel

Jika di ilustrasikan atau dianggap distribusi pengukuran partikel asap GPG sesuai dengan Diagram Normalnya (Gambar 4), maka hasil pengukuran Tim Aerosol Batan menunjukan bahwa, partikel dengan ukuran 0.3 mikron yang memiliki jumlah partikel sebanyak $546 / \mathrm{cm}^{3}$ jika dikaitkan dengan Gambar 4 diperkirakan pada posisi angka "1" dan $136 / \mathrm{cm}^{3}$ pada posisi angka "2" serta diperkirakan masih ada partikel 0.1 mikron dan memiliki jumlah lebih banyak daripada 0.3 mikron jika digambarkan seperti pada Gambar 4 menduduki posisi angka "0" sebagai puncak atau terbanyak dari diagram Normalnya. Asumsi dan perkiraan di atas bisa dibuktikan menunggu hasil pengukuran dan analisis dari Impaktor Kaskade Anderson, kelak. Sampai dengan tulisan ini dibuat, distribusi dan konsentrasi partikel asap dari GPG dari hasil pengukuran Impaktor Kaskade Anderson belum selesai dihitung dan di analisa dari Tim Aerosol Batan. Namun demikian, rekomendasi para ahli baik dari luar maupun dalam negeri menysarakatkan bahwa minimal 100 partikel per $\mathrm{cm}^{3}$ dan diameter (besar) partikel kurang dari 2 mikron. Seperti yang di lakukan penelitian di pegunungan Alpine ditemukan aerosol antara 100-400 partikel per $\mathrm{cm}^{3}$ (Schafer, 1992). Uap air yang tersedia di udara bebas akan 
diperebutkan (kompetisi) oleh partikel sebanyak itu dengan ukuran yang sangat halus, sedemikian sehingga jika sampai berkembang (tumbuh) hingga 20 kalinya (Sarwono, 2013) atau sekitar \pm 6 mikron karena efek higroskopik masih jauh dari fase pembentukan awan dan hujan. Persyaratan minimal mulai terjadi tumbukan dan penggabungan droplet (tetes awan) adalah 18 mikron (Rogers, 1978). Jika kondisi banyaknya droplet hasil pengembunan karena sifat higroskopis dari partikel asap GPG yang dihasilkan hanya mampu pada batas \pm 6 mikron (akhir fase kondensasi) dan jumlahnya banyak sekali serta merata (uniformitas) maka kolom udara akan menjadi stabil. Akibatnya dengan kondisi tersebut di atas akan sulit terbentuk awan dan hujan, dimana mulai masuk fase tumbukan dan penggabungan berkisar minimal \pm 18 mikron. Jarak dan beda jauh antara 6 ke 18 mikron, sehingga ada rantai yang terputus di dalam proses pembentukan awan.

\section{KESIMPULAN}

Hasil sementara dari pengukuran menggunakan Light House (Gambar 2b) dari sebanyak 21 sampling yang dilakukan bahwa partikel asap dari GPG berdiameter 0.3 mikron memiliki jumlah partikel mencapai 495.466.815 $\mathrm{m}^{-3}$ (terbanyak) atau 495 partikel $\mathrm{cm}^{-3}$ dan $51.767 .763 \mathrm{~m}^{-3}$ atau 52 partikel $\mathrm{cm}^{-3}$ (terkecil). Sementara, untuk partikel 0.5 mikron mencapai 84.755.200 partikel $\mathrm{cm}^{-3}$ atau 85 partikel $\mathrm{cm}^{-3}$ (terbanyak) dan $8.969 .923 \mathrm{~m}^{-3}$ atau $9 \mathrm{~cm}^{-3}$ terkecil. Sehingga total partikel [0.3 \& 0.5$]$ mikron berjumlah 547 (terbanyak) dan 94 (terkecil) partikel $\mathrm{cm}^{-3}$. Sedangkan, partikel yang terukur dengan diameter 1.0, 2.5 dan 5.0 mikron di Light House tidak terpantau secara signifikan dalam orde volume (kubik $\left[\mathrm{m}^{-3}\right]$ dan $\mathrm{cc}\left[\mathrm{cm}^{-3}\right]$ ) bahkan NOL atau tidak ada sama sekali (2.5 dan 5) mikron. Hasil pengukuran alat dengan Impaktor Kaskade Anderson, sampai tulisan ini dibuat belum selesai dihitung. Jika di gambarkan pada diagram distribusi (jika dianggap) Normal, dari hasil pengukuran di atas tampak bahwa puncak distribusinya diperkirakan kurang dari 0.3 mikron (antara 0.1 - 0.05 mikron), sebagai "tail" kanan dari "distribusi normal" adalah 1.0 dan 2.5 mikron. Perkiraan dan asumsi tersebut akan dibuktikan dengan menggunakan hasil pengukuran dan perhitungan dari Impaktor Kaskade Anderson yang bisa mengukur partikel terkecil 0.1 mikron, sedangkan Light House terkecil hanya bisa mengukur partikel berdiameter 0.3 mikron.

\section{SARAN DAN WACANA}

Pengukuran partikel yang disampling dari cerobong asap GPG ini baru dalam langkah awal dalam memproduksi partikel untuk memenuhi salah satu syarat dan kriteria (hipotesis dan hasil rekomendasi model serta para ahli) dalam menerapkan Teknologi Modifikasi Cuaca (TMC) dengan metode kompetisi dengan jumlah partikel minmal 100 per $\mathrm{cm}^{3}$ udara dan berdiameter kurang dari 2 mikron. Banyak pertanyaan dan tantangan yang harus dibuktikan dan diukur apakah partikel hasil pengukuran dari asap partikel dari cerobong GPG di ground, sudah mewakili persyaratan hingga mencapai dasar awan. Untuk itu, kedepan perlu dilakukan pengujian dan pengukuran dengan alat ukur yang sama untuk mengukur dari permukaan hingga mendekati dasar awan. Namun sebagai tahapan selanjutnya, kita bisa tempatkan dan operasikan GPG di sekitar menara GBG di Citeko, yang tingginya 50 meter untuk dilakukan pengukuran dengan Light House pada level setiap 10 meter hingga 50 meter. Atau bisa juga di buat model dengan mensimulasikan sampai ketinggian tertentu dan penyebaran hingga radius dengan jarak terjauh, untuk melihat dispersi dan konsentrasi partikel asap yang dimulai dari cerobong GPG, dari permukaan tanah. Namun, sebelum saran dan masukan dari aspek fisis dan model tersebut secara hipothesa pula, dengan memproduksi partikel sebanyak 547 per $\mathrm{cm}^{3}$ selama 24 jam penuh dan dengan memperbanyak GPG (8 unit) atau memperbesar kapasitas (kinerja) maka diharapkan akan terjadi kompetisi atau perebutan uap air oleh banyaknya partikel yang halus dan merata dalam suatu kawasan atau area dengan pengaruh angin yang membawa partikel tersebut selama terjadi kompetisi dan penyerapan dimana partikel higroskopis sebagai $\mathrm{CCN}$ buatan. Semakin banyak partikel yang bisa diproduksi maka tentunya semakin sulit terbentuk awan dan hujan pada daerah yang dilalui atau di dominasi oleh partikel asap GPG tersebut tersebar secara merata. Proses kompetisi sebetulnya tidak harus mencapai dasar awan, karena dengan terjadi kompetisi atau perebutan uap air oleh partikel GPG yang dimulai dari permukaan dalam kenyataan bisa mengalahkan dominasi partikel besar dan higroskopis yang sebagai aktivator cikal bakal terbentuknya awan dan hujan (dari aerosol alami), yang sedikit banyak dapat mengurangi proses pembentukan awan dan hujan pada suatu kawasan tertentu. Saran, hipotesis yang diperkuat dan ditambah dengan peningkatan produksi partikel dari kinerja GPG $\left(>547\right.$ per $\mathrm{cm}^{3}$ ) dan memperbanyak unit GPG 
(>8 unit) serta ditunjang hasil model simulasi (dispersi partikel/panas secara vertikal dan horizontal) kedepan GPG tidak hanya mampu mengurangi hujan (durasi, intensitas dan luasan) akan tetapi bisa digunakan untuk mengurangi dan menghambat pertumbuhan Puting Beliung (lokal), Siklon Tropis (regional) dan Tornado dan Hurricane (di Amerika) kelak.

\section{DAFTAR PUSTAKA}

BROCK C.A., and WILSON J.C., Measurement of Aerosol and Clouds from Aircraft, in Aerosol Measurement : Principles, Techniques and Applications, Van Nostrand Reinhold 1993.

WIENDENSOHLER A., WENDISCH M., HANSON H.C., and ORSINI D., Change the Submicron Particle Size Distribution during a Cloud Process Measured with three DMPS System, J. Aerosol Science 25 (1994) 181-182.

KULMALA M., KORKONEN P., and VESALA T., The Effects of Hygroscopy and Trace Gases on Cloud Droplet Formation, J. Aerosol Science 26 (1995) 891-892.

SCHAFER B., GEORGII H.W., and STAUBES R., Formation and Distribution of Cloud Condensation Nuclei in the Marine Environment, J. Aerosol Science 23 (1992), 865-868.

COLBECK, I., Physical and Chemical Properties of Aerosols, Blackie Academic \& Professional, London, 1998.

HINDS, W.C., Aerosol Technology : Properties, Behavior, and Measurement of Airborne Particles, John Wiley \& Sons Inc., New York, 1982.

BREED, D., R. BRUINTJES, V. SALAZAR, and T. JENSEN, Research Aplication Laboratory, NCAR, Boulder, Co. 80307 USA, 2002.

PUDJADI, E., TAKEDA, K., NAKANE, K., Measurement of Lead Isotope Ratios in Tree Ring Width of the $P$. jamaskura as a Biomonitor of Air Pollution, $48^{\text {th }}$ Annual Meeting of The Ecological Society of Japan, p.268, 2001.

PUDJADI, E., ROU, C., NAKANE K., Decline of $P$. mume and Change in Tree Ring Width and Heavy Metal Concentration, J. Journal of Conservation Ecology, Vol. 9 No.1, p.13-24, 2004.

HARYANTO, U., Penambahan Curah Hujan Melalui Modifikasi Awan: Basis IImiah dan Perkembangannya, Workshop TMCBPPT, Jakarta, 13 maret 2007.

KRAMER, M, BRINKMANN, J, EICHEL, B, JAENICKE, R, SCHELL, D, SCHULE, M,
SCHUTZ, L, Fields Studies on The Cloud Processing of Atmospheric Aerosol Particles and Trace Gases, J. Aerosol Science, Vol. 26, Suppl. 1, p. S893-S894, 1995.

BAYONG, T. Mikrofisika Awan dan Modifisika Cuaca, Workshop Teknologi Modifisika Cuaca, Jakarta, 2007.

SETO, T.H., Paparan Teknologi Modifikasi Cuaca Untuk Mereduksi Curah Hujan, Jakarta, 2013. 